\title{
STRUCTURE AND MECHANICAL PROPERTIES TOOL STEEL AFTER FORGING
}

\author{
'Ladislav KANDER, ${ }^{2}$ Miroslav GREGER \\ 'MATERIAL AND METALLURGICAL RESEARCH Ltd., Pohraniční 693/31, Vitkovice, 703 00, Ostrava, \\ Czech Republic, EU, ladislav.kander@mmvyzkum.cz \\ ${ }^{2} V S ̌ B-T e c h n i c a l$ University of Ostrava, Faculty of Metallurgy and Materials Engineering, \\ Czech Republic, EU, miroslav.greger@vsb.cz
}

https://doi.org/10.37904/metal.2020.3472

\begin{abstract}
The paper deals with comparison of forging technology and selected forming factors on structure of the tool steel EN X160CrMoV12-1. Steel under investigation is a high-alloyed Cr-Mo-V tool steel for exploitation both in hot and cold conditions. The steel is characterised by difficult formability and high resistance to deformation in the whole range of the forging temperatures. The authors compare the structure of forged rods with a diameter of $250 \mathrm{~mm}$, forged products on the radial forging machines with second one forged on hydraulic press CKW 1600.
\end{abstract}

Keywords: Structure, mechanical properties, tool steel, open die forging, radial forging

\section{INTRODUCTION}

Forged bars are still most used semi-product in the industry. Tool steels, in comparison with the structural steels, require at forging of longitudinal forged pieces higher degree of forging than it is expressed by the wellknown equation:

$$
P K=A^{n} \cdot P^{n} \cdot K \geq 3
$$

The degree of forging higher than three forges ensures that in the ingot, the internal discontinuities were already closed and the cast structure was destroyed. In case of the tool steels is, however, required to achieve a refinement of carbides, which requires even higher degree of forging than three. In addition to a higher degree of forging, it is necessary to ensure the structural homogenity of these steels in order to reduce anisotropy of mechanical properties. The level of the obtained properties in tool steels and their scatter depend on variations in the content of the main alloying elements in individual heats, on the degree of forging and on the size of blanks with cast structure. Quality of the blanks depends on the suitable metallurgical treatment and on the level of the steelmaking technology (e.g. secondary metallurgy refining and alloying, vacuum casting, etc.)

\section{STRUCTURE OF AS-CAST TOOL STEELS}

Carbides of tool steels can be from the viewpoint of their formation divided into primary (carbide structures crystallising from the melt) and secondary (carbides forming from the solid phase). The primary carbides segregate from the liquid phase. They create usually a complex structural system:

a) Complex carbide of the MC type. Tungsten is usually the main element. The carbide may have different chemical composition, which depends on the amount of alloying elements and the conditions of solidification.

b) Complex carbide $\mathrm{M}_{2} \mathrm{C}$ occurs in the high-alloyed tool steels with higher Mo contents. Its distribution in the structure is heterogeneous. The clusters may still contain the carbides of the MC type, e.g. the carbide VC is formed in the steels alloyed with vanadium. 
The secondary carbides are segregated from austenite in the following modifications: complex carbides of the type $\mathrm{M}_{23} \mathrm{C}_{6}$, where also other carbide-forming elements are formed apart from the prevailing share of $\mathrm{Fe}$ and $\mathrm{Cr}$ [1]. In the steels alloyed by high content of Czech Republic, they have an approximate composition $\mathrm{Fe}_{15} \mathrm{Cr}_{8} \mathrm{C}_{6}$. Complex carbide of the type $\mathrm{M}_{3} \mathrm{C}$, in which $\mathrm{Fe}$ is also one of the main component. The carbide segregates mostly during transformation of austenite to martensitic. The last type is the carbide MC, which is usually segregated in primary carbides or which is created by disintegration of the complex carbide $\mathrm{M}_{23} \mathrm{C}_{6}$. This carbide has also different chemical composition and its existence is related to the temperature, cooling rate and the amount of vanadium in steels. Composition of individual carbides and conditions of their formation are a function of time, temperature and concentration carbide-forming elements [2]. It means that existence of different types of carbides and conditions of their formation in single variant of chemical composition of the steel are quite variable. We therefore cannot expect that the given type of steel will always have carbides with exactly the same chemical composition.

\section{FORMABILITY OF TOOL STEELS}

Tool steels belong to the steels with reduced plasticity (formability). Deterioration of formability is linked to the segregation of brittle eutectic phase along the grain boundaries, especially in steels in the as-cast state. The formability increases during the forging with the increasing degree of destruction of eutectic mesh. The formability of the tool steels decreases with the increasing degree of alloying. The formability decreases in the tool steels at the places of segregation, containing higher amount of carbon, due to decrease of the melting temperature. These factors influencing the formability of high-alloyed steels are a function of the following physics-chemical factors: the type of crystalline structure, purity of grain boundaries, inter-atomic forces in the crystal, structural construction and the temperature factor [3]. The above-mentioned factors are dependent on the strain rate, magnitude of deformation, unevenness of deformation.

One of the decisive factors influencing the resistance to deformation and formability is the state of stress influencing the conditions of forging. The highest formability is achieved at the state of compressive stress with exclusion of tensile stresses, which are the main cause of failure of the forged piece at forming. The stress state during forging is a result of a complex effect of stress from burdening forces and from additional stresses induced by an external friction and by uneven deformation [4,5]. The stress state during free forging can be expressed in different ways, e.g, with use of the mean indicator of the stress state vs:

$v_{s}=\frac{\sigma_{s}}{\sigma_{p}}=\frac{\sigma_{1}+\sigma_{2}+\sigma_{3}}{3\left(\sigma_{1}-\sigma_{3}\right)}$

Where $\sigma_{1}, \sigma_{2}, \sigma_{3}$ are the main stresses, $\sigma_{s}$ is an octahedral stress and $\sigma_{p}$ is resistance to deformation of the forged steel.

The marginal formability increases with the decreasing value $v_{s}$. the highest formability is achieved when the relationship: $\sigma_{1}=\sigma_{2}$ is valid. At forging on the flat anvils, the main stress acts in the direction of the main principal changes of the shape. The compressive stress $\sigma_{h}$ in the direction of the decreasing height [6]:

$\sigma_{h}=\frac{F_{k}}{l_{z} \cdot b_{s}}$

Where $F_{k}$ is the forging force $[\mathrm{N}], \mathrm{I}_{\mathrm{z}}$ is the length of action [mm], $b_{s}$ is the mean width of the elongated bar [mm].

The stress $\sigma_{l}$ acts in longitudinal direction (in the direction of elongation) :

$\sigma_{l}=0,5\left(\mu \cdot \sigma_{p} \cdot \frac{l_{z}}{h_{o}}\right)$

Where $\mu$ is a friction coefficient and $h_{o}$ is the height of the elongated bar.

The following relation is used for calculation of the stress in the direction of the width: 


$$
\sigma_{b}=0,5\left(\mu \cdot \sigma_{p} \cdot \frac{b}{h}\right)
$$

If the shape of anvil limits the spreading (e.g. at elongation on the machines GFM), it is then possible to use for forging of round bars the following relation [7]:

$$
\sigma_{b}=\frac{F_{b}}{l_{z} \cdot d}
$$

Where $F_{b}$ is the forging force in the direction of the width of the forged piece $[\mathrm{N}], \mathrm{d}$ is the diameter of the forged piece [mm].

At elongation in industrial conditions of forging; shops the rate $\sigma_{s} / \sigma_{p}$ may vary within the interval from +0.5 to -2.0 , i.e. from the prevailing tensile state to a distinctive compressive state of stress.

\section{EFFECTS AT FORGING OF THE STEEL EN X160CrMoV12-1}

Our next investigation was focused on the steel EN X160CrMoV12-1. Chemical composition of the steel grade EN X160CrMoV12-1 is shown in Table 1.

Table 1 Chemical composition of the steel EN X160CrMoV12-1 in wt. \%

\begin{tabular}{|c|c|c|c|c|c|c|c|c|}
\hline Steel grade & C & Mn & Si & Cr & Mo & V & P & S \\
\hline X160CrMoV12-1 & 1.42 & 0.40 & 0.25 & 11.70 & 0.50 & 0.25 & 0.015 & 0.018 \\
\hline
\end{tabular}

During forming surface and internal defects are being formed for two main causes. The defects can be transferred to the forged piece from the ingot, or the defects arise at forging because of unsatisfactory state of stress and uneven deformation. Plastic deformation during forging is always uneven. The causes of uneven deformation can be divided into internal and external.

Internal causes comprise heterogeneity of the chemical composition, diverse orientation of crystals, defects in crystalline structure, existence of foreign impurities in the basic matrix. Furthermore, it is an uneven temperature of the forged steel when the middle, or surface layers may have considerably different temperature.

External factors causing uneven deformation may comprise contact friction or low external energy of deformation, which, together with high resistance to deformation of steel causes the fact that penetration of deformation affects only the surface areas.

In the central parts of the formed piece are for this reason generated large tensile stresses. Tensile stresses are the most common initiators of defects, especially at forming of the cast structure. Uneven deformation during forging depends significantly on the geometric shape of the deformation zone [8].

At elongation with use of straight anvils (elongation on ordinary forging presses), the magnitude of uneven deformation is the function of the relative length of the stroke $\left(I_{z} / h_{o}\right)$, relative reduction $\Delta h / h_{o}$ and the shape indicator of the cross-section $\left(b_{o} / h_{o}\right)$. Elongation by small relative length of stroke achieves the maximal intensity of elongation and the number of passes is minimal.

On the other hand, in the case of small relative stroke the number of working strokes increases. The optimum performance is achieved at $I_{z} / h_{0}=0.5$. That's why at forging of large ingots, which cannot be rammed, it is appropriate to use $I_{z} / h_{0}=0.5$ to 1 .

The chosen value $I_{z} / h_{0}$ determines formability of the steel. It proved good at forging of large ingots to cant only when the ratio $b_{i} / h_{i}=1.8$ to 2 was achieved. The axial part is forged the best on the low flattened piece. This procedure cannot be recommended for forging of steels with reduced formability. After canting the flattened piece is, forged upright and tensile stresses develop on the lateral surface. 
Elongation by shaped anvils is advantageous particularly for the forged pieces of circular section with reduced formability. During forging in the zone of deformation, the compressive stresses prevail

\section{INFLUENCE OF THE TOOLS' SHAPE ON EVOLUTION OF STEEL STRUCTURE}

An analysis of the structure of the forged bars on the press CKW 1600 and on the radial forging machine was performed. It concerned assessment of the microstructure, micro-purity and grain size, presence of porosity, cracks and inclusions. The bars were forged from the ingots K21 to approximately the same diameter. The degree of forging calculated with use of the equation (1) reached the value of 3.5 .

Microstructure was assessed (see Figures 1, 2) in the selected areas of the cross section, i.e. in the subsurface areas and at the distance of $0.25 \mathrm{D}$ and $0.5 \mathrm{D}$ of the bar diameter, as well as the overall distribution of primary carbides in the structure (Figure 3).

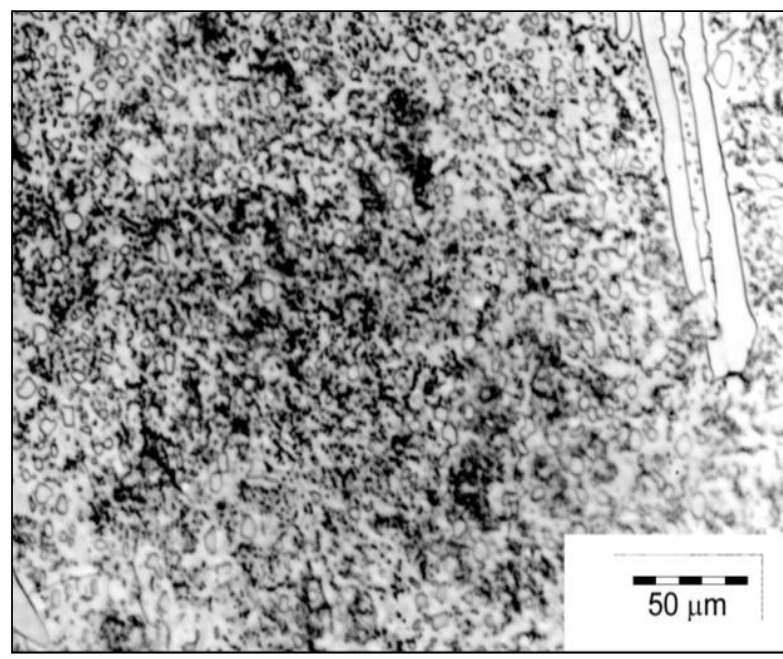

a)

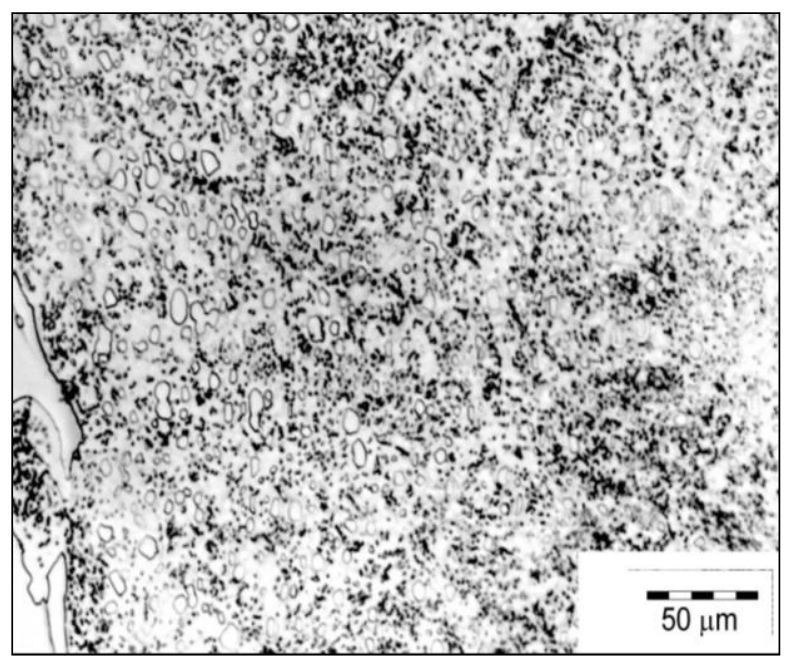

b)

Figure 1 Structure of the steel EN X160CrMoV12-1 after forging on the radial forging machine: a) subsurface area, b) distance $0.25 \mathrm{D}$ from the surface (ingot $\mathrm{K} 21$, bar diameter $250 \mathrm{~mm}$, degree of forging 3.5)

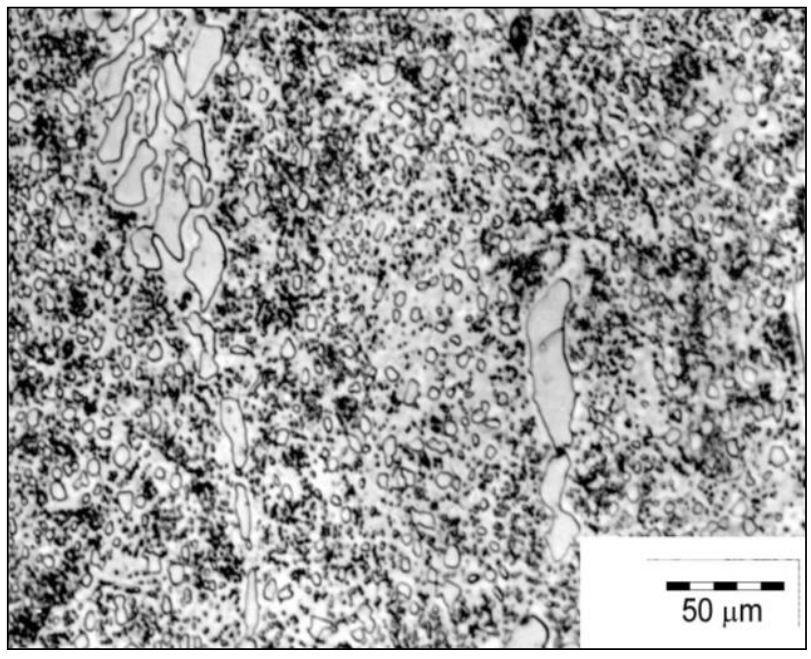

a)

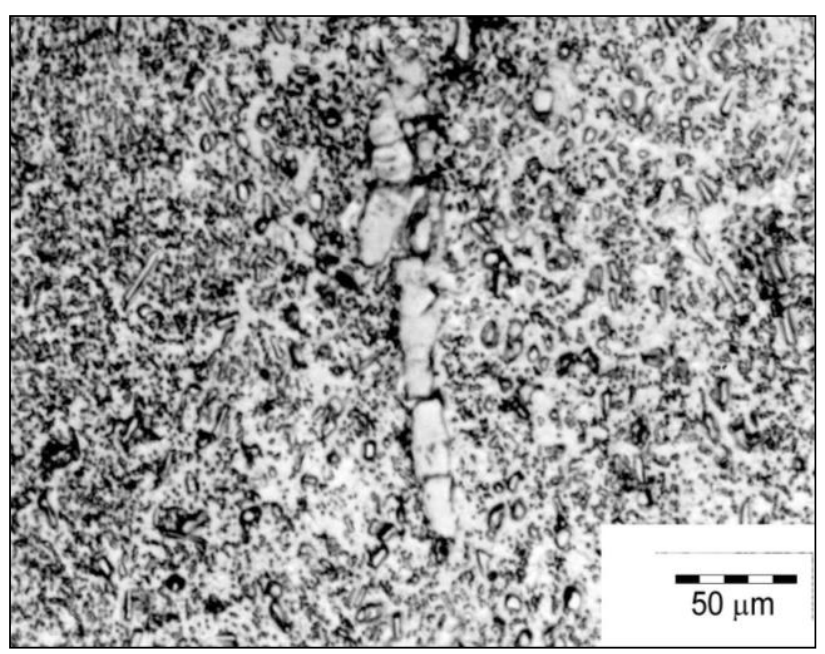

b)

Figure 2 Structure of the steel EN X160CrMoV12-1 after forging on the: a) radial forging machine, b) press CKW 1600 (degree of forging 3.5, ingot K21, bar diameter $250 \mathrm{~mm}$, distance $0.5 \mathrm{D}$ from the surface) 


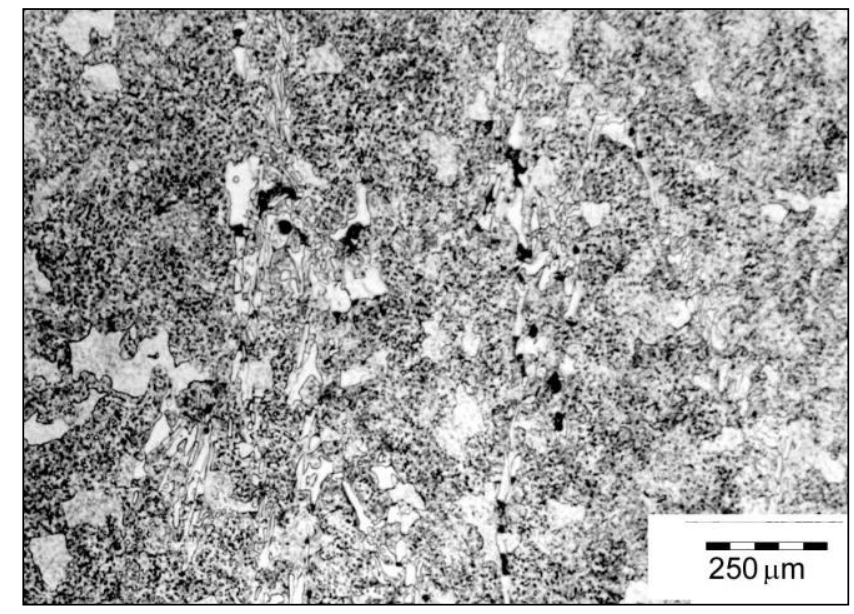

a)

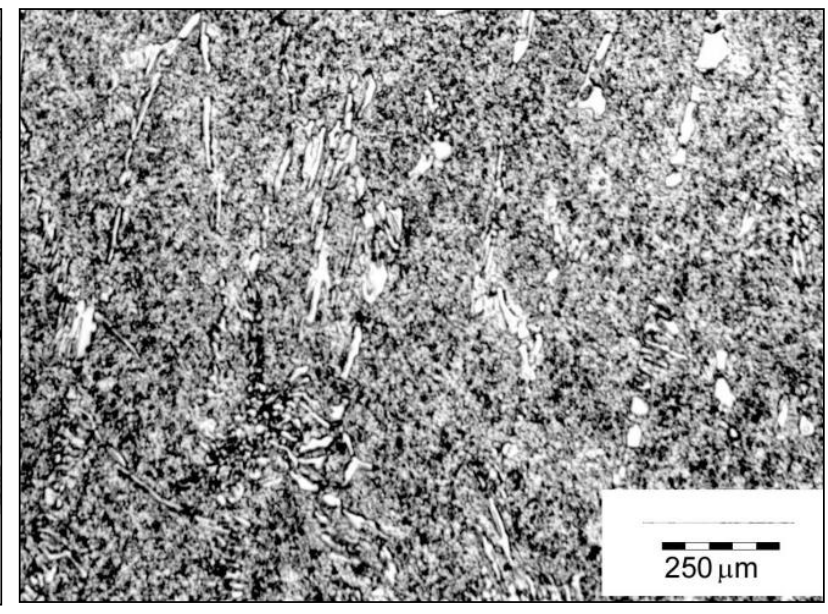

b)

Figure 3 Distribution of carbides along the cross-section of the bar after forging: a) on the radial forging machine; b) on the press CKW 1600

\section{SUMMARY AND DISCUSSION OF THE ACHIEVED RESULTS}

Structural homogeneity along cross-section of the forged round bars depends not only on metallurgical properties of the input blank, but also on the type of used forming machine. Comparison of macro-structure of bars revealed that at forging on the press at the same degree of forging the porosity in axial parts of the forged bar is closed more perfectly. The reason for this is higher share of shearing deformation in this area at forging on hydraulic press. Another possible cause of this difference is probably also the higher degree of forging on the press. The calculation of the degree of forging according to the relation (1) is based on the share of crosssections $K=S_{o} / S_{k}$. At forging on the press with use of the scheme, square - rectangle - square - circular section the spreading takes place. However, the value of the increment of the degree of forging at the shape changes square - rectangle is according to the relation (1) not included into the overall degree of forging. For calculation of the degree of forging in individual passes, it is possible to use also the equation:

$$
K=\frac{1}{1-\varepsilon(1-f)}
$$

Where: $\varepsilon$ is relative deformation, $f$ is indicator of spreading $(f=0.19$ to 0.5$)$.

When summing the individual degrees of forging according to the equation (7) we get the overall degree of forging $\mathrm{K}_{\Sigma}$ higher than the quoted value $\mathrm{K}=3.5$ that was calculated according to the relation (1). Another cause may consist in the fact that at forging on the radial forging machine a universal pressure acts only at the final stage of forging.

Results of metallographic analysis prove that internal non-integrities in the steel structure may be formed under influence of: change of volume of liquid and solid phase, carbidic segregates and micro-cracks in the segregates. In the steel of the type $\mathrm{Cr}-\mathrm{Mo}-\mathrm{V}$, the prevailing part of shrinkage porosities is transferred into the forged piece from the ingot and it can be removed only at the degree of forging $K>4.5$. Forging on the extension machine is characterised by more favourable state of stress than in the case of forging on the press, but with smaller share of shearing deformations, which, however, are the decisive factor for closing of nonintegrities. Microstructure on Figure 1, 2 is formed by basic matrix (ferrite, sorbit), in which massive particles of primary carbides are situated. Comparison of microstructure of the bars forged on the extension machine and on the press CKW 1600 (Figure 3) makes it possible to predict in structure of the steel forged on the forging machine more massive primary carbides. Grain size on both figures varies around the 7 (according to the ASTM). 


\section{CONCLUSION}

Effect of various forging technology on structure of tool steel X160CrMoV12-1 has been studied. Structure of the forged bars made of the tool steel EN X160CrMoV12-1 is influenced both by the forging technology and by technology of production of input blanks - ingots. In order to achieve high quality of structure it is necessary to choose a suitable shape and dimensions of anvils in dependence on the selected forging machine. Quality of structure achieved by forging depends in great extent, namely at the degrees of forging around $\mathrm{K}=3$, on the quality of the cast - primary structure of the ingot. Perfect forming of the structure can be achieved by forging with higher share of shearing deformations.

\section{ACKNOWLEDGEMENTS}

This paper was created in the frame of the Institutional support for long-term and conceptual development of a research organization in 2019, provided by the Ministry of Industry and Trade of the Czech Republic.

\section{REFERENCES}

[1] FILA, P., BALCAR, M., MARTINEK, L. et al. Development of new types of tool steels designed for Forging dies. Kovárenství (Forging). 2010, September, no. 38, pp.11-14.

[2] BALA, P., KRAWCZYK, J. Transformations during quenching and tempering of hot-work tool steel. In METAL 2009, 19. - 21. 5 2009, Hradec nad Moravicí: Tanger 2009, CD ROM.

[3] GHAEI, A., MOVAHHEDY, M.R., TAHERI, A.K. Study of the effects of die geometry on deformation in the radial forging proces. J. Materials Processing Technology. 2005, vol., pp. 156-163.

[4] SALLIT, I., RICHARD, C., BÉRANGER, G. et al. Experimental study of wear behaviour of hot forging tool steels under dry conditions 40CrMoV13. Tribology Letters. 2002, vol. 12, no. 3, pp. 147-152.

[5] STEBloV, A.B., LENARTOVICH, D.V., PONKRATIN, E.I. New steel for hot forging dies. Metallurgist. 2006, vol. 50 , no. $1-2$, pp. 61-64.

[6] WOLFGARTEN, M., ROSENSTOCK, D., SCHAEFFER, L., HIRT G. Implementation of an open-die forging process for large hollow shafts for wind power plants with respect to an optimized microstructure. La Metallurgia Italiana. 2015, no. 4, pp. $43-49$.

[7] DOMBLESKY, J.P., RAJIV, S. Development and validation of Finite element model for multiplepas radial forging. Journal of Materials Processing Technology. 1995, vol. 55, iss. 3-4, pp. 432- 441.

[8] GREGER, M., KIML, K., JíLEK, L. et al. Forging parameters influence on structure of ČSN 19572 steel. Kovárenství (Forging). 2008, no. 32, pp. 22-27. 